\title{
Variabilidade de colônias de Kabatiella zeae em meios de cultura e morfologia de isolados do fungo
}

\author{
Rubia C. Camochena, Idalmir dos Santos \& Gustavo Malagi \\ Universidade Tecnológica Federal do Paraná-UTFPR, Campus Pato Branco, Cx. Postal 571, CEP 85501-970, Pato Branco, \\ PR, Brasil
}

Autor para correspondência: Idalmir dos Santos, e-mail: idalmir@utfpr.edu.br

\begin{abstract}
RESUMO
Trinta e cinco isolados de Kabatiella zea obtidos de diferentes materiais genéticos de milho foram utilizados para avaliar as características morfológicas e crescimento micelial. Os meios de cultura utilizados foram BSA (batata, sacarose e ágar), MA (malte e ágar), AV (aveia e ágar) e FA (farinha de milho e ágar). Discos de $5 \mathrm{~mm}$ de diâmetro, retirados das margens de colônias crescidas em meio BSA, por 10 dias, foram colocadas no centro das placas contendo os respectivos meios de cultura. As placas foram incubadas a $24^{\circ} \mathrm{C}$ com fotoperíodo de 12 horas, por 10 dias. As características morfológicas dos isolados e as características das colônias foram avaliadas em BSA e o crescimento micelial, nos quatro meios. Todos os isolados apresentaram variabilidade em relação aos meios de cultura. Observou-se que a dimensão dos conídios variou de 3-4 x 27-33 $\mu \mathrm{m}$, de largura e comprimento, respectivamente. Verificou-se que $80 \%$ dos isolados apresentaram coloração clara (rosa) e aspecto Coriáceo e enrugado, e o maior crescimento micelial foi observado no meio BSA.
\end{abstract}

Palavras chave: Zea mays, milho, mancha ocular.

\begin{abstract}
Morphological variability of Kabatiella zeae isolates and aspect of fungus colonies in culture media

Thirty-five Kabatiella zeae isolates from different corn genetic materials were used to evaluate their morphological characteristics and mycelial growth. The following culture media were used: PSA (potato, sucrose, and agar), MA (malt and agar), OA (oat and agar) and CA (corn meal and agar). Disks ( $5 \mathrm{~mm}$ diameter) were removed from the margins of colonies grown on PSA medium for 10 days and placed at the center of dishes containing the corresponding culture media. The dishes were incubated at $24^{\circ} \mathrm{C}$ and a 12 -hour photoperiod for 10 days. The morphological characteristics of the isolates as well as colony characteristics were evaluated in PSA, while mycelial growth was evaluated in the four media. All isolates showed variability in relation to the culture media. Spore size ranged from 3-4 $\times 27-$ $33 \mu \mathrm{m}$ in width and length, respectively. Eighty percent of the isolates had a light (pink) color and a coriaceous and wrinkled aspect; the highest mycelial growth was observed in the PSA medium.
\end{abstract}

Keywords: Zea mays, corn, eyespot.

O fungo Kabatiella zeae Narita \& Hiratsuka Dingley, ainda não foi estudado no Brasil, mas, nos últimos anos está se tornando importante para a cultura do milho. O referido patógeno é agente causal da mancha ocular, que foi descrita pela primeira vez no Japão em 1959. Em seguida, foi registrada nos Estados Unidos, Canadá, Argentina, Áustria, França, Alemanha, Iugoslávia e Nova Zelândia (Reifschneider \& Arny, 1983).

No Brasil a mancha ocular foi registrada em Dourados MS no ano agrícola de 1982/83 (Esteves, 1984). Somente 20 anos mais tarde foi identificada em híbridos de milho na safra de 2004/05, em Santa Catarina e Paraná (Santos et al., 2007).

A mancha ocular do milho, doença até o presente estudo, considerada secundária, vem adquirindo importância em função da susceptibilidade apresentada pela maioria dos genótipos de milho e da intensidade com que vem se manifestando. A doença já foi detectada em mais de 30 genótipos de milho chegando a 17\% de severidade média nos mais suscetíveis (Camochena et al., 2007). Os principais sintomas, desta doença são lesões translúcidas, circulares a ovais ( $1-4 \mathrm{~mm}$ de diâmetro) com um halo amarelado; algumas manchas podem coalescer formando grandes áreas necróticas. Inicialmente, a lesão apresenta um aspecto encharcado e seu centro adquire, em pouco tempo, uma coloração parda a creme circundada por um halo de cor marrom, púrpura ou parda que, por sua vez é circundado por um halo amarelado o que dá à lesão o aspecto de um olho quando observada contra a claridade. Além das folhas, os sintomas podem ocorrer nos colmos e espigas (Arny et al., 1971).

Reifschneider \& Arny (1980) estudaram a variabilidade cultural e morfológica de $K$. zeae e concluíram que não houve diferenças significativas para largura dos conídios de vários isolados analisados, com média de 2,5 micrômetros $(\mu \mathrm{m})$. $\mathrm{O}$ crescimento micelial variou entre 1,1 e 4,4 mm/dia e a temperatura ótima para o desenvolvimento de $60 \%$ dos isolados foi de $24^{\circ} \mathrm{C}$. Complementaram o 
trabalho classificando dois tipos básicos de colônias, as de coloração clara $(18 \%)$ ou escuras $(82 \%)$ e todas com aspecto coreáceo.

$\mathrm{Na}$ literatura internacional as informações ainda são escassas a respeito da referida doença e de seu agente causal. No Brasil, os trabalhos de pesquisa com a mancha ocular ainda estão em fase inicial, devido à constatação e ao aumento da importância desta doença serem relativamente recentes nas condições brasileiras. Assim, a variação das características morfológicas de K. zeae, isolado de diferentes materiais genéticos de milho, ainda não foi estudada em nosso país.

O conhecimento das características morfológicas das colônias, micélio e conídios, são importantes para que possam ser desenvolvidos estudos relacionados ao patógeno, analisando suas características fisiológicas, como composição química dos meios de cultura, que servirão para determinar a eficiência da sua esporulação e crescimento micelial (Bogo et al., 2008).

Os microrganismos, de modo geral, possuem como característica uma grande variabilidade que pode refletir em sua morfologia, fisiologia ou patogenicidade. Eles possuem uma capacidade muito variável na utilização de diferentes meios de cultura, produção de toxinas ou outros metabólitos que resultam, às vezes, em variações na agressividade dos biótipos (Machado, 1980).

Segundo Fernandez (1993), alguns meios pobres em carboidratos, mas ricos em substâncias vegetais influenciam na esporulação de fungos fitopatogênicos, induzindo-a ou aumentando-a. Os substratos como o ágar-água, sem fontes de nutrientes, são utilizados quando se deseja que o desenvolvimento do patógeno a ser estudado se dê a partir dos nutrientes presentes no tecido contaminado, de onde se está tentando isolar esses microrganismos.

Considerando-se que não são conhecidas as variações nas características morfológicas de isolados de $K$. zeae, originários de diferentes locais e genótipos, no Brasil, seu crescimento micelial em relação ao tipo de substrato utilizado, comportamento em relação ao tamanho de conídios, aspecto e coloração de colônias, faz-se necessário a obtenção desses dados para subsidiar novas pesquisas pois, segundo Menezes (2004), o conhecimento da morfologia dos isolados fúngicos é uma etapa importante no processo inicial das pesquisas de qualquer patossistema. O sucesso infectivo do patógeno pode depender da variabilidade, pois influi na resistência do hospedeiro (Guseva et al., 1979). Uma vez obtida a caracterização de diversos isolados, o estudo complementar da identificação de raças poderá auxiliar na obtenção de materiais genéticos de milho resistentes, bem como evitar a recomendação errônea destes a regiões predisponentes à doença.

O presente trabalho teve como objetivo caracterizar a variabilidade de $K$. zeae quanto ao crescimento micelial e tamanho de conídios, em diferentes substratos, coloração e aspecto da colônia em BSA.
Foram utilizados 35 isolados de $K$. zeae coletados no Estado do Paraná e Santa Catarina e, posteriormente, identificados de acordo com o híbrido de origem e a ordem de isolamento. Os isolados 1 a 28 são oriundos de Pato Branco-PR, 29 e 30 de Dois Vizinhos-PR, 31 de ClevelândiaPR, 32 a 34 de Planalto-SC, 35 a 37 de Abelardo Luz-SC e o isolado 39 de Foz do Iguaçú-PR. O isolado 1 é originário do híbrido de milho PENTA, 2-BALU 761, 3-DKB 234, 4-AS 1565, 5-SG 212, 6-SPRINT, 7-AX 890, 11-AX 895, 12-PREMIUM FLEX, 13-CARGO, 14-DKB 950, 15-SG 6412, 16-32R21, 17-DKB 566, 18-AG9020, 19-ATTACK, 20-AGN 35A42, 21-SG6418, 22-AS 1570, 23-BALU 184, 24-DKB 214, 25-AS 3466, 26-DKB 979, 27-CD 306, 28IPR 121, 29-ADVANCE, 30-2B 710, 31-DKB 234, 3232R48, 33-30R50, 34-30F53, 35-MAXIMUS, 36-SPRINT, 37-TORK, 39-não especificado.

Para obtenção dos isolados partes de folhas infectadas pelo patógeno foram esterilizadas em hipoclorito de sódio $2 \%$ por 1 minuto e, em seguida, lavados em água esterilizada por três vezes. Após, com auxílio de pinça e bisturi, foram recortados pequenos pedaços de folhas com lesões que foram colocados em meio de cultura BSA (batata, sacarose, ágar). As placas foram mantidas em estufa tipo BOD, a $24^{\circ} \mathrm{C}$ com fotoperíodo de 12 horas por 5 dias para o desenvolvimento do patógeno. Após o isolamento e obtenção de culturas puras do patógeno, foram obtidas culturas monospóricas de cada isolado as quais foram mantidas em BSA a $4^{\circ} \mathrm{C}$.

A caracterização dos isolados foi realizada com as colônias que previamente foram cultivadas em BSA e incubadas com fotoperíodo de 12 horas a $24^{\circ} \mathrm{C}$. O aspecto e a coloração das colônias foram avaliados aos 5 e 10 dias de incubação.

Para a mensuração do tamanho dos conídios, foram preparadas lâminas com uma gota de água, onde foram adicionados os conídios do patógeno com auxílio de agulha histológica. Cinquenta conídios de cada isolado foram mensurados quanto à largura e comprimento médios com auxílio de microscópio óptico com 40x de aumento. O valor correspondente às dimensões das imagens foi avaliado em micrômetros $(\mu \mathrm{m})$.

A avaliação do crescimento micelial foi realizada com os seguintes meios de cultura: a) BSA; b) AV (flocos de aveia, $75 \mathrm{~g}$; ágar, $17 \mathrm{~g}$; água destilada, $1000 \mathrm{~mL}$ ); c) FA (fubá de milho, $60 \mathrm{~g}$; ágar, $17 \mathrm{~g}$; água destilada, 1000 $\mathrm{mL}$ ); d) MA (Malte, $25 \mathrm{~g}$; ágar, $15 \mathrm{~g}$; água destilada, $1000 \mathrm{~mL}$ ).

A partir de culturas puras dos isolados de K. zeae, desenvolvidos por 10 dias em BSA com fotoperíodo de 12 horas, foram retirados, das bordas da colônia, discos de aproximadamente $5 \mathrm{~mm}$ de diâmetro contendo estruturas fúngicas do patógeno, os quais foram depositados no centro de placas de Petri contendo os diferentes meios, as quais foram incubadas em estufa B.O.D. a $24 \pm 1^{\circ} \mathrm{C}$ com fotoperíodo de 12 horas por 10 dias.

As avaliações finais de crescimento micelial foram realizadas no $10^{\circ}$ dia de incubação, com auxílio de 
uma régua graduada, registrando-se as medidas médias perpendicularmente, $\mathrm{em} \mathrm{cm}$.

Os ensaios foram conduzidos em delineamento inteiramente ao acaso com os tratamentos distribuídos em um fatorial $35 \times 4 \times 3$ (isolados x meios de cultura $\mathrm{x}$ repetições). As médias foram comparadas pelo teste de Scott-Knott, ao nível de 5\% de probabilidade de erro.
Houve variação quanto ao aspecto e coloração das colônias (Tabela 1). Todas as colônias no meio de cultura BSA apresentaram-se com aspecto coreáceo, enrugado e algumas ainda, com halos concêntricos. A coloração variou de branco a salmão aos 5 dias de desenvolvimento e rosa a oliva aos dez dias.

As colônias produziram conídios hialinos não septados, longos e curvos e com dimensões variando de 3-

TABELA 1 - Dimensões de conídios, aspecto e coloração de colônias de $K$. zeae, em meio de cultura BSA

\begin{tabular}{|c|c|c|c|c|}
\hline \multirow[t]{2}{*}{ Isolados } & \multirow{2}{*}{$\begin{array}{c}\text { Dimensões } \\
\text { Comprimento x Larg ura em } \mu \mathrm{m}\end{array}$} & \multirow[t]{2}{*}{ Aspecto da colônia } & \multicolumn{2}{|c|}{ Coloração } \\
\hline & & & 5 dias & 10 dias \\
\hline 1 & $31 \times 3$ & Coreáceo & $\mathrm{AC}$ & $\mathrm{Rc}$ \\
\hline 2 & $31 \times 3$ & Coreáceo com halos & $\mathrm{AC}$ & $\mathrm{Rc}$ \\
\hline 3 & $31 \times 3$ & Coreáceo & S & $\mathrm{Rc}$ \\
\hline 4 & $30 \times 3$ & Coreáceo com halos & $\mathrm{C}$ & ReBo \\
\hline 5 & $28 \times 3$ & Coreáceo & $\mathrm{C}$ & $\mathrm{Rc}$ \\
\hline 6 & $30 \times 3$ & Coreáceo & $\mathrm{B}$ & $\mathrm{Rc}$ \\
\hline 7 & $32 \times 3$ & Coreáceo & $\mathrm{B}$ & $\mathrm{Rc}$ \\
\hline 11 & $30 \times 3$ & Coreáceo & $\mathrm{C}$ & $\mathrm{Rc}$ \\
\hline 12 & $31 \times 3$ & Coreáceo com halos & $\mathrm{B}$ & $\mathrm{Rc}$ \\
\hline 13 & $30 \times 3$ & Coreáceo com halos & $\mathrm{S}$ & $\mathrm{Rc}$ \\
\hline 14 & $30 \times 3$ & Coreáceo com halos & $\mathrm{A}$ & $\mathrm{RecBb}$ \\
\hline 15 & $29 \times 3$ & Coreáceo com halos & $\mathrm{B}$ & $\mathrm{Rc}$ \\
\hline 16 & $31 \times 3$ & Coreáceo com halos & $\mathrm{S}$ & $\mathrm{Rc}$ \\
\hline 17 & $31 \times 3$ & Coreáceo & $\mathrm{C}$ & ReBo \\
\hline 18 & $29 \times 3$ & Coreáceo & $\mathrm{S}$ & $\mathrm{Rc}$ \\
\hline 19 & $29 \times 3$ & Coreáceo & $\mathrm{B}$ & $\mathrm{Rc}$ \\
\hline 20 & $29 \times 3$ & Coreáceo & $\mathrm{BO}$ & $\mathrm{Rc}$ \\
\hline 21 & $31 \times 3$ & Coreáceo com halos & $\mathrm{B}$ & $\mathrm{Rc}$ \\
\hline 22 & $29 \times 3$ & Coreáceo com halos & $\mathrm{B}$ & $\mathrm{Rc}$ \\
\hline 23 & $30 \times 3$ & Coreáceo com halos & $\mathrm{B}$ & $\mathrm{Rc}$ \\
\hline 24 & $28 \times 3$ & Coreáceo com halos & $\mathrm{S}$ & $\mathrm{S}$ \\
\hline 25 & $27 \times 4$ & Coreáceo & $\mathrm{S}$ & Rcmo \\
\hline 26 & $29 \times 3$ & Coreáceo & B & $\mathrm{S}$ \\
\hline 27 & $31 \times 3$ & Coreáceo & $\mathrm{B}$ & S \\
\hline 28 & $33 \times 3$ & Coreáceo & $\mathrm{B}$ & OcRe \\
\hline 29 & $31 \times 4$ & Coreáceo com halos & $\mathrm{S}$ & $\mathrm{RcBb}$ \\
\hline 30 & $28 \times 3$ & Coreáceo & $\mathrm{S}$ & $\mathrm{Rc}$ \\
\hline 31 & $30 \times 3$ & Coreáceo com halos & $\mathrm{S}$ & $\mathrm{Rc}$ \\
\hline 32 & $27 \times 3$ & Coreáceo com halos & $\mathrm{C}$ & $\mathrm{Rc}$ \\
\hline 33 & $32 \times 3$ & Coreáceo & $\mathrm{B}$ & $\operatorname{Re}$ \\
\hline 34 & $32 \times 3$ & Coreáceo & $\mathrm{B}$ & $\operatorname{Re}$ \\
\hline 35 & $30 \times 3$ & Coreáceo & $\mathrm{B}$ & $\mathrm{Rc}$ \\
\hline 36 & $32 \times 3$ & Coreáceo & $\mathrm{C}$ & RecmoBb \\
\hline 37 & $30 \times 3$ & Coreáceo com halos & $\mathrm{C}$ & $\mathrm{Rc}$ \\
\hline 39 & $30 \times 3$ & Coreáceo & $\mathrm{C}$ & $\mathrm{Rc}$ \\
\hline
\end{tabular}

*AC-amarelo claro; S-salmão; C-creme; B-branco; Re-rosa escuro; Rc-rosa claro; RccBb-rosa claro no centro e bordas branca; RecBb-rosa escuro no centro e borda branca; ReBo-rosa escuro no centro borda oliva; Rmo-rosa com manchas oliva; OcRe-oliva no centro e bordas rosa escuro; RBb-rosa com borda branca; RecmoBb- rosa escuro no centro com manchas oliva e borda branca. 
$4 \times$ 27-33 $\mu \mathrm{m}$. Esta variação coincide com os resultados encontrados por Arny et al (1971), que em estudos sobre a mancha ocular do milho, na America do norte, descreveram dimensões semelhantes de conídios, que variaram de 3-4 x $18-33 \mu \mathrm{m}$, variação esta que foi influenciada pelo substrato utilizado.

As colônias dos isolados 1, 3, 5, 6, 7, 11, 17, 18, 19, $20,25,26,27,28,30,33,34,35,36$, e 39 apresentaram aspecto coreáceo e aveludado da colônia, e as dos demais isolados, aspecto coriáceo com halos concêntricos. Levic \& Pencic (1990), em estudos com fontes de carbono, nitrogênio e compostos sulfurosos para o crescimento de $K$. zeae, constataram que com diferentes compostos nitrogenados a maioria das colônias apresentou micélio compacto, coreáceo e dobrado, e algumas com halos concêntricos. Os meios de cultura podem induzir os isolados a comportamentos diferentes (Muller, 2000). Alguns nutrientes podem ser metabolizados com velocidades diferentes, levando à síntese de outras moléculas ou produtos que podem influenciar no mecanismo de crescimento do fungo (Griffin, 1993). A coloração rosa, aos 10 dias de desenvolvimento predominou em $80 \%$ dos isolados (Figura 1). Após as avaliações as placas foram mantidas nas mesmas condições de crescimento, e a maioria das colônias adquiriu coloração negra aos 20 dias.

Houve interação significativa entre os isolados com relação ao crescimento micelial em todos os meios de cultura utilizados. Em observação comparativa entre o crescimento nos quatro meios de cultura, observase que dos 14 isolados (letra maiúscula na linha) que apresentaram maior crescimento micelial nos quatro meios, 9 desenvolveram-se em MA, 3 em BSA, 1 em FA e 1 em AV. Ou seja, o MA proporcionou melhor crescimento micelial ao maior número de isolados, em relação aos outros meios (Tabela 2).

Para descrever a diferença de crescimento micelial entre os isolados, para cada meio de cultura, foram separados 3 grupos, com base na análise estatística, sendo alto, médio e baixo crescimento. A separação de grupos serve para mostrar a habilidade dos isolados em utilizar as diferentes fontes de nutrientes. No meio de cultura BSA não houve diferença significativa entre os isolados, onde o crescimento micelial variou de 1,9 a 4,3 cm. Entretanto, o isolado 19 diferiu dos demais, apresentando crescimento micelial de $1,7 \mathrm{~cm}$.

Em relação ao meio FA, o maior crescimento foi observado para o isolado 25 , com $2,7 \mathrm{~cm}$. No grupo de crescimento micelial médio estão 18 dos isolados que não diferiram entre si estatisticamente. $\mathrm{O}$ restante dos isolados permaneceram no grupo de baixo crescimento, com variação de 0,5 a $1,4 \mathrm{~cm}$.

$\mathrm{O}$ meio de cultura AV proporcionou melhor crescimento micelial para 14 isolados. Os isolados classificados como de crescimento médio formaram o maior grupo, 19 isolados, variando de 1,5 a $2,0 \mathrm{~cm}$, e o restante, classificados como de crescimento baixo $(0,5 \mathrm{~cm})$.
O melhor crescimento micelial observado no meio MA foi para os isolados 11 e 22, com 2,3 cm, não diferindo entre si estatisticamente. $\mathrm{O}$ grupo de crescimento médio foi composto pela maioria dos isolados, 18 isolados, variando de 1,7 a 2,2. O restante dos isolados foi classificado como de crescimento baixo para este meio de cultura, com variação de 0,8 a $1,6 \mathrm{~cm}$.

Pereira et al. (2006), em estudos sobre características fisiológicas e culturais de isolados de Lasiodiplodia theobromae concluíram que alguns fungos podem utilizar a energia unicamente para o crescimento, enquanto outros, utilizam sua energia para esporulação. Isso pode justificar o maior ou menor crescimento micelial de $K$. zeae nos diferentes meios de cultura.

Altas taxas de crescimento foram observadas em BDA e MA em estudos sobre variabilidade cultural e morfológica de K. zeae, sugerindo que a variação existente entre os isolados, em taxas de crescimento, deveriam ser utilizadas para classificação das espécies (Reifschneider \& Arny, 1980). Nada foi encontrado na literatura sobre inoculação cruzada dos isolados para analisar se existe reação diferencial entre várias cultivares de milho. Em outros estudos, os autores concluem que diferentes tipos de nutrientes expressam os tipos de colônia e que o crescimento das colônias em diferentes fontes de carbono é mais intenso depois de 10 dias (Levic \& Pencic, 1990).

Este estudo demonstrou uma variabilidade morfológica das colônias em meio de cultura BSA e variação no crescimento micelial em todos os meios testados. A maioria dos isolados apresentou um alto crescimento micelial em meio de cultura BSA, concordando, em parte, com os estudos de Reifschneider \& Arny (1980), nos Estados Unidos, que observaram o maior crescimento micelial de isolados de $K$. zeae em meio BDA e MA, em relação a $\mathrm{CZ}$ e V8. Isso mostra uma pequena semelhança entre os isolados do Brasil com outros isolados estudados fora deste país. Os mesmos autores observaram que com 10 dias de incubação, 18\% das colônias, de 28 isolados, apresentaramse de coloração clara, contrariando o presente trabalho, no qual, as colônias de coloração clara (rosa) predominaram, com $80 \%$ de freqüência.

Com relação ao aspecto e coloração das colônias, houve variação para todos os isolados, sendo que, com 10 dias de incubação, $80 \%$ dos 35 isolados estudados, apresentaram coloração clara, e todos os isolados apresentaram aspecto coreáceo e enrugado. Em observação ao crescimento micelial percebeu-se que o maior número de isolados preferiu o meio MA em relação aos outros meios. Todavia, o maior grupo de alto crescimento micelial foi constatado em BSA.

Uma vez identificada a variabilidade morfológica e o meio de cultura mais adequado ao crescimento do patógeno, é possível conduzir estudos que avaliem as variações de agressividade de cada isolado. Identificando-se os isolados mais agressivos os mesmos poderão ser submetidos a trabalhos de avaliação de sensibilidade a fungicidas e sua influência na reação de materiais genéticos de milho. Esses 


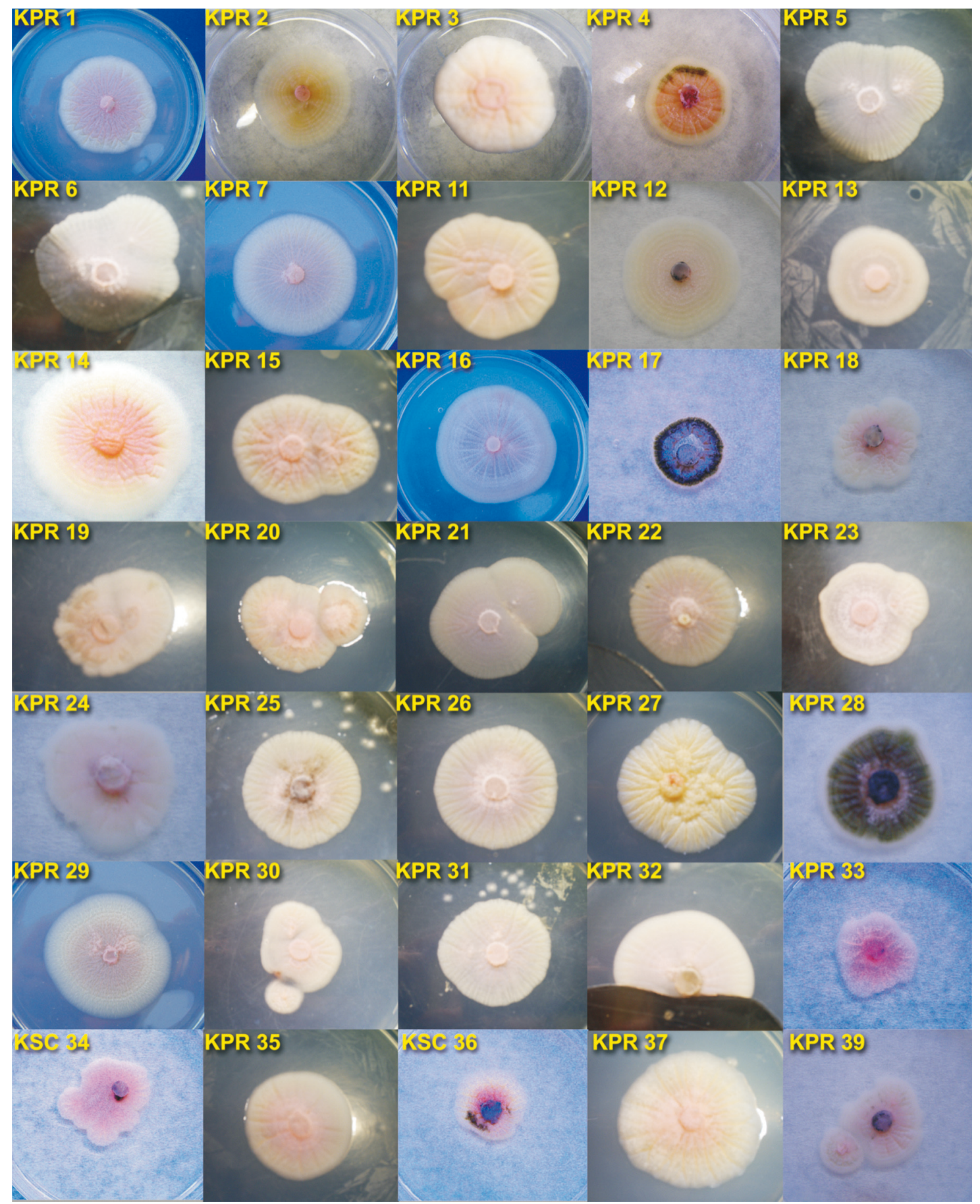

FIGURA 1 - Aspecto e coloração de colônias de isolados de K. zeae, obtidos de diferentes materiais genéticos de milho aos 10 dias de incubação em BSA (batata, sacarose, ágar).

dados servirão de subsídios para pesquisas que visem minimizar os prejuízos que possam vir a ser causados por este patógeno, através de métodos de controle químico ou genético, que tornem possível o manejo adequado da doença.

Sendo assim, o presente trabalho permitiu concluir que todos os isolados apresentaram variabilidade em relação aos meios de cultura. A dimensão dos conídios variou de 3-4 x 27-33 $\mu \mathrm{m}$, de largura e comprimento, respectivamente.

Verificou-se que $80 \%$ dos isolados apresentaram coloração clara (rosa) e aspecto coreáceo e enrugado, e o maior crescimento micelial foi observado no meio BSA. 
TABELA 2 - Crescimento micelial (cm) de K. zeae em diferentes meios de cultura aos 10 dias de incubação

\begin{tabular}{|c|c|c|c|c|}
\hline \multirow[b]{2}{*}{ Isolados } & \multicolumn{4}{|c|}{ Meios de cultura * } \\
\hline & BSA & FA & $\mathbf{A V}$ & MA \\
\hline 1 & $3,3 \mathrm{aD}$ & $1,4 \mathrm{cC}$ & $2,0 \mathrm{bC}$ & $2,0 \mathrm{BC}$ \\
\hline 2 & $4,2 \mathrm{aA}$ & $1,6 \mathrm{bB}$ & $2,1 \mathrm{aC}$ & $2,0 \mathrm{bC}$ \\
\hline 3 & $2,5 \mathrm{aF}$ & $0,7 \mathrm{dE}$ & $2,1 \mathrm{aC}$ & $1,8 \mathrm{bB}$ \\
\hline 4 & $2,6 \mathrm{aF}$ & $1,5 \mathrm{bC}$ & $1,8 \mathrm{bD}$ & $1,8 \mathrm{bB}$ \\
\hline 5 & $3,7 \mathrm{aC}$ & $1,6 \mathrm{bC}$ & $1,5 \mathrm{bE}$ & $1,6 \mathrm{cC}$ \\
\hline 6 & $4,3 \mathrm{aA}$ & $1,7 \mathrm{bB}$ & $1,8 \mathrm{bD}$ & $2,0 \mathrm{bC}$ \\
\hline 7 & $3,4 \mathrm{aD}$ & $1,5 \mathrm{bC}$ & $1,7 \mathrm{bD}$ & $1,7 \mathrm{bC}$ \\
\hline 11 & $2,3 \mathrm{aG}$ & $1,5 \mathrm{bC}$ & $2,0 \mathrm{bC}$ & $2,3 \mathrm{aA}$ \\
\hline 12 & $2,9 \mathrm{aE}$ & $1,6 \mathrm{bC}$ & $1,9 \mathrm{bD}$ & $1,9 \mathrm{bB}$ \\
\hline 13 & $1,9 \mathrm{aH}$ & $1,5 \mathrm{bC}$ & $1,5 \mathrm{bE}$ & $2,0 \mathrm{bC}$ \\
\hline 14 & $4,3 \mathrm{aA}$ & $1,4 \mathrm{cC}$ & $1,8 \mathrm{bD}$ & $1,5 \mathrm{Cc}$ \\
\hline 15 & $3,8 \mathrm{aC}$ & $1,8 \mathrm{bB}$ & $2,0 \mathrm{bC}$ & $2,2 \mathrm{bA}$ \\
\hline 16 & $3,8 \mathrm{aC}$ & $0,9 \mathrm{cD}$ & $2,2 \mathrm{aB}$ & $2,2 \mathrm{bA}$ \\
\hline 17 & $3,3 \mathrm{aD}$ & $0,8 \mathrm{bD}$ & $0,5 \mathrm{cF}$ & $0,8 \mathrm{cD}$ \\
\hline 18 & $2,6 \mathrm{aF}$ & $0,5 \mathrm{dE}$ & $1,9 \mathrm{bC}$ & $2,0 \mathrm{bB}$ \\
\hline 19 & $1,7 \mathrm{bH}$ & $1,7 \mathrm{bB}$ & $2,8 \mathrm{aA}$ & $1,4 \mathrm{cC}$ \\
\hline 20 & $2,6 \mathrm{aF}$ & $0,5 \mathrm{dE}$ & $0,5 \mathrm{cF}$ & $1,6 \mathrm{cC}$ \\
\hline 21 & $3,4 \mathrm{aD}$ & $0,5 \mathrm{dE}$ & $2,0 \mathrm{bC}$ & $2,2 \mathrm{bA}$ \\
\hline 22 & $2,0 \mathrm{aH}$ & $1,0 \mathrm{cD}$ & $2,1 \mathrm{aC}$ & $2,3 \mathrm{aA}$ \\
\hline 23 & $2,1 \mathrm{aH}$ & $0,8 \mathrm{cD}$ & $2,1 \mathrm{aC}$ & $1,6 \mathrm{cC}$ \\
\hline 24 & $3,0 \mathrm{aE}$ & $1,7 \mathrm{bB}$ & $2,2 \mathrm{aB}$ & $2,2 \mathrm{bA}$ \\
\hline 25 & $2,7 \mathrm{aF}$ & $2,7 \mathrm{aA}$ & $2,3 \mathrm{aB}$ & $1,5 \mathrm{cC}$ \\
\hline 26 & $3,5 \mathrm{aD}$ & $1,8 \mathrm{bB}$ & $2,1 \mathrm{aC}$ & $1,5 \mathrm{cC}$ \\
\hline 27 & $3,3 \mathrm{aD}$ & $1,0 \mathrm{cD}$ & $1,9 \mathrm{bC}$ & $2,2 \mathrm{bA}$ \\
\hline 28 & $2,9 \mathrm{aE}$ & $1,5 \mathrm{bC}$ & $2,0 \mathrm{bC}$ & $2,2 \mathrm{bA}$ \\
\hline 29 & $3,0 \mathrm{aE}$ & $1,4 \mathrm{cC}$ & $2,1 \mathrm{aC}$ & $2,1 \mathrm{bB}$ \\
\hline 30 & $2,2 \mathrm{aG}$ & $1,1 \mathrm{cD}$ & $1,8 \mathrm{bD}$ & $1,6 \mathrm{cC}$ \\
\hline 31 & $2,7 \mathrm{aF}$ & $1,5 \mathrm{bC}$ & $2,0 \mathrm{bC}$ & $1,3 \mathrm{cC}$ \\
\hline 32 & $3,9 \mathrm{aB}$ & $1,4 \mathrm{cC}$ & $2,2 \mathrm{aB}$ & $2,0 \mathrm{bC}$ \\
\hline 33 & $2,6 \mathrm{aF}$ & $0,8 \mathrm{dD}$ & $2,1 \mathrm{aC}$ & $2,2 \mathrm{bA}$ \\
\hline 34 & $3,7 \mathrm{aC}$ & $0,6 \mathrm{dE}$ & $2,0 \mathrm{bC}$ & $1,0 \mathrm{dD}$ \\
\hline 35 & $2,1 \mathrm{aH}$ & $1,1 \mathrm{bD}$ & $2,4 \mathrm{aB}$ & $1,1 \mathrm{cD}$ \\
\hline 36 & $2,3 \mathrm{aG}$ & $0,5 \mathrm{dE}$ & $2,4 \mathrm{aB}$ & $1,3 \mathrm{cC}$ \\
\hline 37 & $3,9 \mathrm{aB}$ & $1,9 \mathrm{bB}$ & $1,8 \mathrm{bD}$ & $1,1 \mathrm{cD}$ \\
\hline 39 & $2,5 \mathrm{aF}$ & $1,7 \mathrm{bB}$ & $2,0 \mathrm{bC}$ & $1,1 \mathrm{Cd}$ \\
\hline
\end{tabular}

*As médias seguidas de mesma letra minúscula na coluna, e maiúscula na linha, não diferem entre si pelo teste Scott-Knott ao nível de 5\% de probabilidade de erro.

\section{REFERÊNCIAS BIBLIOGRÁFICAS}

Arny DC, Smalley EB, Ullstrup AJ, Worf GL, Ahrens RW (1971) Eyespot of mayze, a disease new to north America.
Phytopathology 61:54-57.

Bogo A, Maffioletti MA, Sanhueza RMV, Casa RT (2008) Caracterização morfológica de isolados de Cryptosporiopsis perennans em diferente meios de cultura. Tropical Plant 
Pathology 33: 248-251.

Camochena RC, Santos I dos, Malagi G (2007) Avaliação da sensibilidade de genótipos de milho à mancha ocular, causada por Kabatiella zeae. Fitopatologia Brasileira 32: 225.

Esteves A (1984) Incidência de doenças, sob condições de campo, em cultivares de milho (Zea mays), em Dourados. Fitopatologia Brasileira 9:155-160.

Fernadez MR (1993) Manual para laboratório de fitopatologia. Ed. Passo Fundo: Embrapa-CNPT.

Griffin DH (1993) Fungal Physiology. New York: John Wiley \& Sons.

Guseva NN, Levitin MM, Mikhailova LA (1979) Genetic mechanisms of variability in phytopathogenic fungi. Acta Phytopathologica Academiae Scientiarium Hungaricae 14:441447.

Levic J, Pencic V (1990) Utilization of carbon, nitrogen and sulfur compounds by Kabatiella zeae Narita et Hiratsuka . Phytopathology 128:321-332.

Machado AA (1980) Esporulação de Macrophomina phaseolina (Tass.) Goid. e variabilidade do método de inoculação de esporos em estudos de seleção de germoplasma resistente. Dissertação de Mestrado. Piracicaba. Escola Superior de Agricultura "Luiz de Queiroz"/USP.

Menezes M, Assis SMP (2004) Guia prático para fungos fitopatogênicos. Recife: Imprensa Universitária. 188p

Müller MVG (2000) O estudo da variabilidade morfológica e o uso de amplificação randômica de DNA polimórfico (RAPD) na caracterização de isolados de Bipolaris sorokiniana. 2000. Dissertação de Mestrado. Porto Alegre. Universidade Federal do Rio Grande do Sul.

Pereira L, Silva GS, Ribeiro VQ (2006) Caracterização fisiológica, cultural e patogênica de diferentes isolados de Lasiodiplodia theobromae. Fitopatologia Brasileira 31:572-578.

Reifschneider FJB, Arny DC (1983) Yeld loss of maize caused by Kabatiella zeae. Phytopathology 73: 607-609.

Reifschneider FJB, Arny DC (1980) Cultural and morphological variability of Kabatiella zeae. Transactions of the British Mycological Society. 75: 239-241.

Santos I dos, Silva A, Malagi G (2007) Ocorrência de Mancha Ocular em Milho Causada por Kabatiella zeae no Paraná e em Santa Catarina. Fitopatologia Brasileira 32:359.

TPP 9003 - Recebido 12 Janiero 2009 - Aceito 14 Maio 2010 Editor de Seção: Carlos R. Casela 